\title{
Acoustic Imaging of Underground Storage Tank Wastes
}

S. J. Mech

Date Published

September 1995

Prepared for the U.S. Department of Energy

Assistant Secretary for Environmental Management

(2)

Approved for public release 


\section{DISCLAIMER}

Portions of this document may be illegible in electronic image products. Images are produced from the best available original document. 
WHC-EP-0870

Revision 0

\section{Acoustic Imaging of Underground Storage Tank Wastes}

Prepared for the U.S. Department of Energy

Assistant Secretary for Environmental Management

(2) Westinghouse

Hanford Company Richland, Washington

Management and Operations Contractor for the

U.S. Department of Energy under Contract DE-AC06-87RL10930

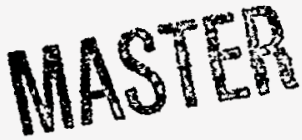

Approved for public release 
LEGAL DISCLAIMER

This report was prepared as an account of work sponsored by an agency of the United States Government. Neither the United States Government nor any agency thereof, nor any of their employees, nor any of their contractors, subcontractors or their employees, makes any warranty, express or implied, or assumes any legal liability or responsibility for the accuracy, completeness, or any third party's use or the results of such use of any information, apparatus, product, or process disclosed, or represents that its use would not infringe privately owned rights. Reference herein to any specific commercial product, process, or service by trade name. trademark, manufacturer, or otherwise, does not necessarily constitute or imply its endorsement, recommendation, or favoring by the United States Government or any agency thereof or its contractors or subcontractors. The views and opinions of authors expressed herein do not necessarily state or reflect those of the United States Government or any agency thereof.

This report has been reproduced from the best available copy. Available in paper copy and microfiche.

Available to the U.S. Department of Energy and its contractors from

U.S. Department of Energy

Office of Scientific and Technical Information (OSTI)

P.O. Box 62

Oak Ridge, TN 37831

(615) $576-8401$

Available to the public from the U.S. Department of Commerce National Technical Information Service (NTIS)

5285 Port Royal Road

Springfield, VA 22161

(703) $487 \cdot 4650$

Printed in the United States of Ameries

DISCLM-1.CHP (8-95) 


\section{RELEASE AUTHORIZATION}

Document Number: WHC-EP-0870, REV. 0

Document Title: Acoustic Imaging of Underground Storage Tank Wastes

Release Date: . $\quad 9 / 28 / 95$

\section{This document was reviewed following the procedures described in WHC-CM-3-4 and is:}

APPROVED FOR PUBLIC RELEASE

WHC Information Release Administration Specialist:

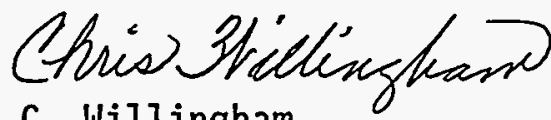

C. Witlingham

TRADEMARK DISCLAIMER. Reference herein to any specific comercial product, process, or service by trade name, trademark, manufacturer, or otherwise, does not necessarily constitute or imply its endorsement, recommendation, or favoring by the United States Government or any agency thereof or its contractors or subcontractors.

This report has been reproduced from the best available copy. Available in paper copy and microfiche. Printed in the United States of America. Avajlable to the U.S. Department of Energy and its contractors from:

U.S. Department of Energy

Office of Scientific and Technical Information (OSTI)

P.0. Box 62

Oak Ridge, TN 37831

Telephone: (615) 576-8401

Available to the public from:

U.S. Department of Commerce

National Technical Information Service (NTIS)

5285 Port Royal Road

Springfield, VA 22161

Telephone: (703) 487-4650 
HHC-EP-0870, Rev. 0

- ACOUSTIC IMAGING OF UNDERGROUND STORAGE TANK WASTES

S. J. Mech

Hestinghouse Hanford Company

$8 / 95$ 


\section{SUMMARY}

Acoustics is a potential tool to determine the properties of high level wastes stored in Underground Storage Tanks. Some acoustic properties were successfulty measured by a limited demonstration conducted in 114-TX. This accomplishment provides the basis for expanded efforts to qualify techniques which depend on the acoustic properties of tank wastes. This work is being sponsored by the Department of Energy under the Office of Science and Technology.

In FY-1994, Timited Tank Waste Remediation Systems .EM-30 support was available at Hanford and Los Alamos National Laboratory. The Massachusetts Institute of Technology (MIT) and Earth Resources Laboratory (ERL) were engaged for analys is support, and Elohi Geophysics, Inc. for seismic testing services. Westinghouse-Hanford Company provided the testing and training, supplied the special engineering and safety analysis equipment and procedures, and provided the trained operators for the actual tank operations.

On 11/9/94, 1imited in-tank tests were successfully conducted in tank 114-TX. This stabilized Single Shell Tank was reported as containing 16.8 feet of waste, the lower 6.28 feet of which contained interstitial 1iquid. Testing was conducted over the lower 12 feet, between two Liquid Observation Wells thirty feet apart. The "quick-look" data was reviewed on-site by MIT and Elohi.

Building on a geophysics technology base and MIT's advanced technology developed by DOE's Basic Energy Science (ER-15), ERL determined that:

- acoustic imaging of the tank wastes is feasible,

- waste simulants do not accurately represent the acoustic properties of the tank wastes in situ,

- the acoustic velocity in waste is approximately $3000 \mathrm{M} / \mathrm{sec}$, (faster than in simulants).

- the tank content is essentially solid (within the volumes examined), and the acoustic energy at approximately 900 hertz penetrated the best.

A second test will be performed to refine and validate this information. It is important that a variety of tanks and. waste forms be assessed, as well as possible deployment methods. And finally, these seismic methods should be assessed for detecting pipe leaks in the soil. Specifically as a data fusion candidate.

The anticipated results are:

- Deployment methods will be evaluated

- Verify ability to determine tank waste phases

The resources employed or considered for collaboration include Massachusetts Institute of Technology Earth Resources Laboratory, Coleman Research Corporation, Electrical Resistance Tomography (Lawrence Livermore National Labs, Blackhawk-Coleman, Elohi Geophysics, Inc., Texas Tech University, Ames Lab, Los ATamos National Laboratory. 
WHC-EP-0870, ReV. 0

Background

Hanford has 177 underground storage tanks (UST) containing radioactive and chemical wastes generated during Hanford's weapons production mission. The current challenge is to remediate these hazardous wastes volumes. Development of effective methods and equipment will require reasonable estimates of the tank waste's physical properties and their distribution. Acoustic imaging has the potential to provide some of this information.

The acoustic properties of tank wastes have never been measured in place, however some measured and estimated values for some of these properties have been reported . In the absence of better information, these values have been assumed correct. The fact is, that like the physical properties and their distribution, the acoustic properties of these materials remain essentially unknown.

In FY-94, a 7 imited program was initiated to assess the feasibility of using acoustic methods to characterize the volumes of Hanford's Underground Storage Tanks (UST) in situ. The strategy was to use methods and equipment commonly used in geophysics. Existing expertise and resources located at Los Alamos National Laboratory (LANL), the Earth Resources Laboratory (ERL) at Massachusetts Institute of Technology (MIT) and Elohi Geophysical, Inc. (EGI), Houston Texas. EGI's responsibility was to supply and operate the test equipment to support the base line demonstration of acoustics imaging in Hanford's tank wastes. MIT was to analyze this data and assess the viability of using nonlinear tomographic methods to image the tank's contents. The LANL contribution was the initial technical oversite and creation of the technical team.

This in situ activity potentially would provide three essential elements of characterization information not otherwise available:

- An image of the tank waste stratification.

- The relative physical properties of these wastes.

- A baseline for verifying waste simulant's acoustic properties.

\section{Objectives}

The primary objectives established for this limited test were:

- To assess the feasibility of using acoustic methods in UST wastes. If shown to be feasible, develop and assess imaging strategies.

- To assess the validity of using chemical simulants for the development of acoustic methods and equipment.

1 Representative velocities of sound in tank wastes are presented in Appendix A.

Page 2 of 7 
WHC-EP-0870, Rev 0

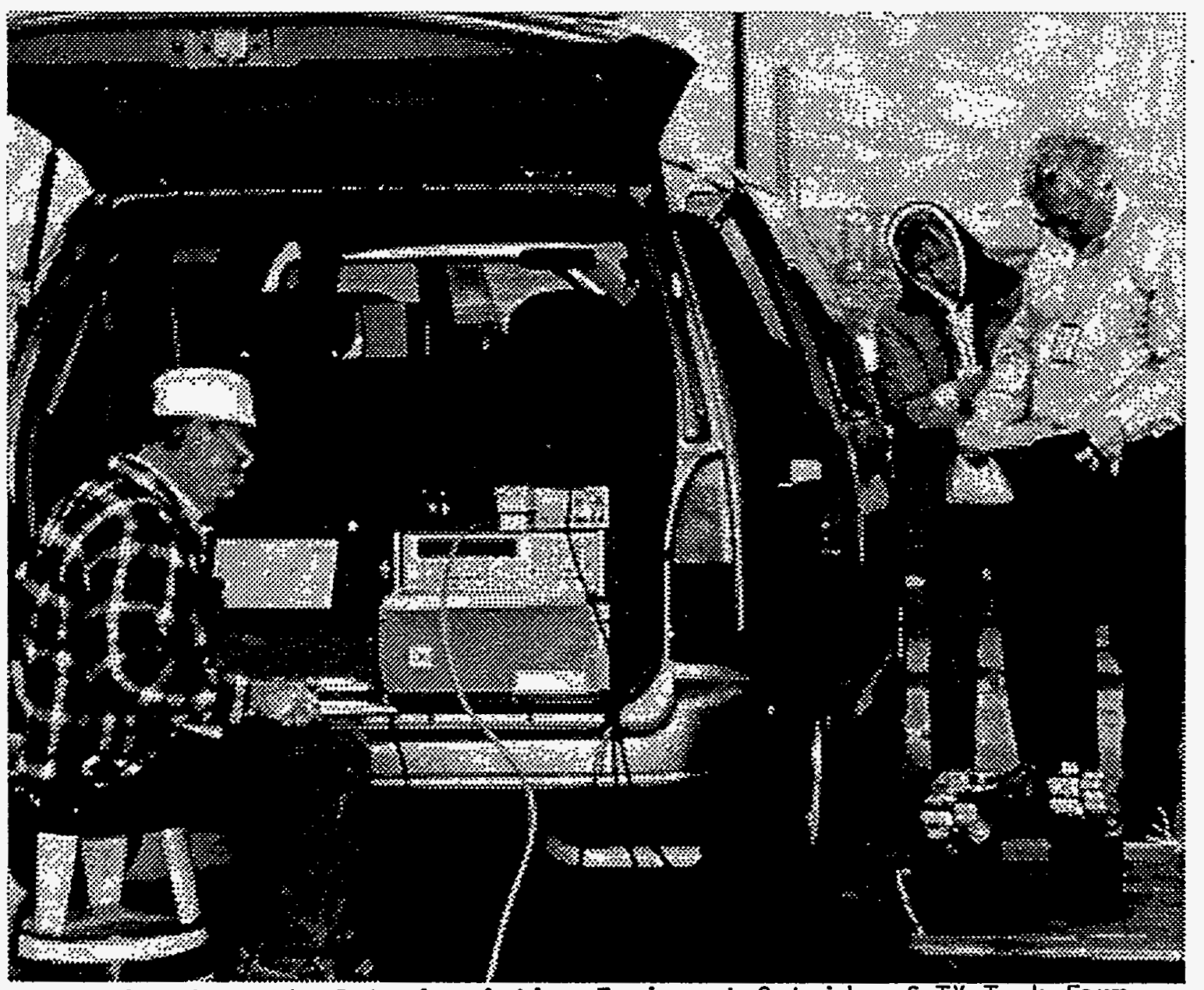

Figure 1. Acoustic Data Acquistion Equipment Outside of TX Tank Farm Boundary. (photo courtesy of EGI) 


$$
\text { WHC-EP-0870, Rev } 0
$$

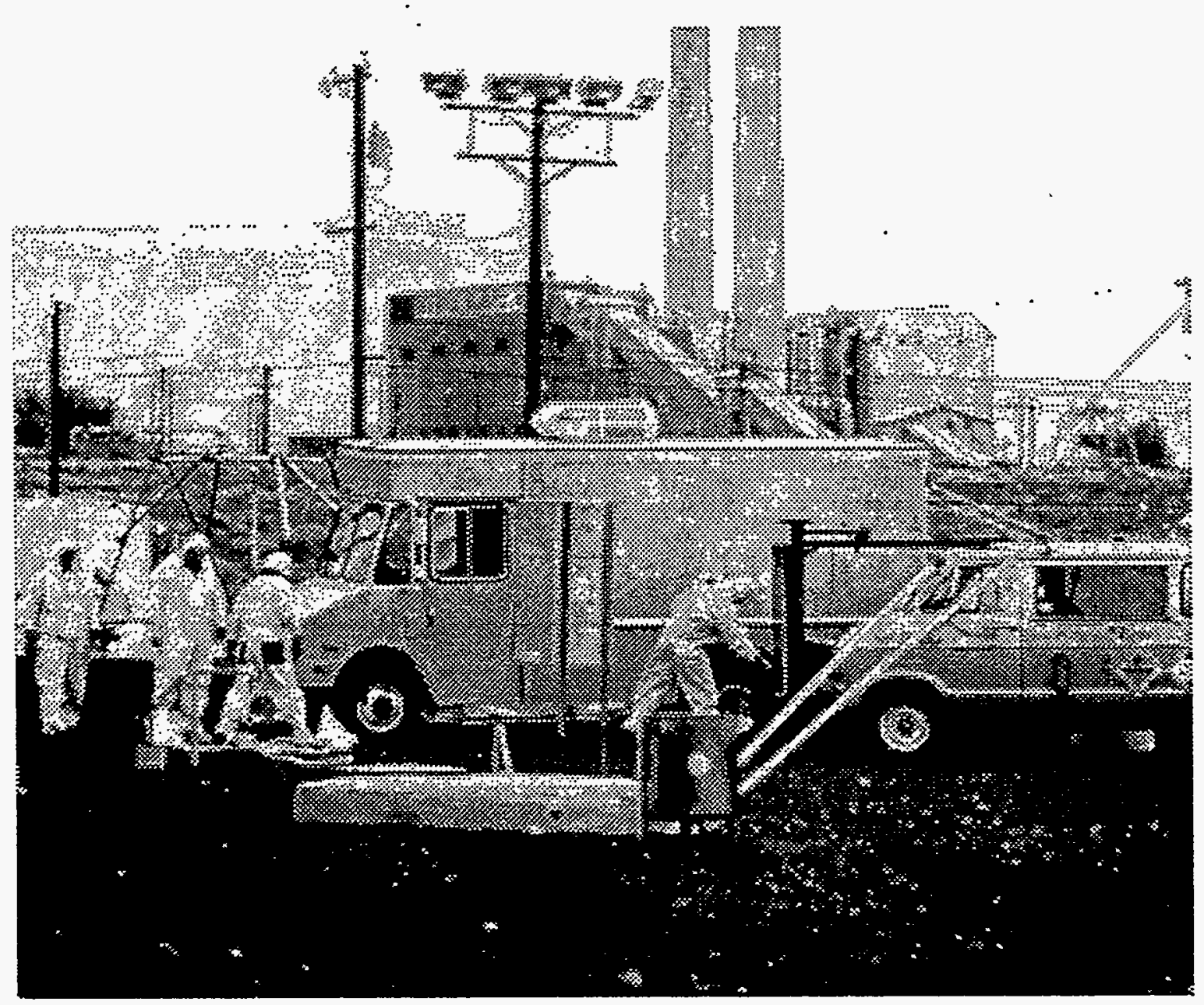

Figure 2. Operations Crew Deploying Transducers in Tank 114-TX. (photo courtesy of EGI) 


\section{WHC-EP-0870, Rev. 0}

\section{Test Tank 114- TX}

Tank 114-TX, a stabilized, single shel1 UST in the 200 West Tank Farm area was identified as the best available candidate for the demonstration. The main reason for it's selection was that it is the only tank with two fiber-glass Liquid Observation Wells (LOWs) installed. These LOWs, normally used to host non-invasive liquid Tevel sensing instrumentation, are four-inch diameter, fiber glass, dry observation wells which extend from ground level to the bottom of the tank. These penetrations permit the acoustic transmitter and receivers to be deployed into the waste volume without contacting the wastes. Water will be added to the LOWs to couple the acoustic energy from the transducer to the LOW wa77.

The plan of action was to interrogate an aperture 30 feet wide by 12 feet high, relative to the bottom of the tank. The test configuration ${ }^{2}$ was:

- TweTve feet of water was added to the two LOWs which were 30 feet apart.

- Total tank capacity - 750,000 ga\}. (22.5 feet)

- Total waste volume - 535,000 ga1. (16.8 feet)

- Total Tiquid (included in the total waste) $-15,000$ gal. (measured at 6.26 feet)

\section{Issues To Be Assessed}

The testing strategy focussed on three issues critical to the viability of acoustic imaging in tank wastes:

- would acoustic energy be adequately transmitted between the LOWs and the wastes.

The assumption was that there would be sufficient coupling where there was interstitial 7iquid (from the bottom to approximately 6 feet). Coupling was expected to deteriorate rapidly above that level.

- were conventional geophysical methods and equipment capable of assessing the velocity of sound in actual tank wastes in situ.

did the chemical simulant of the UST wastes adequately models the acoustic properties of the tank wastes.

${ }^{2}$ Appendix B, Figures 2 and 3.

Page 5 of 7 
WHC-EP-0870, Rev. 0

Analysis

Although information exists relative to the properties and behavior of acoustics applied to the geophysical world, in-tank acoustics present a unique challenge. Specificaliy the challenge was to assure that within the 114-TX boundary the observed information could be defended. An example was that the "first arrival" of the acoustic energy could be unambiguously identified even in the presence of other data caused by acoustic energy taking some indirect path(s).

In the absence of measured properties, certain assumptions were made regarding the behavior of acoustic in tank wastes. The analysis of the data was to assess the validity of those assumptions. Specifically:

- The velocity of sound in the tank wastes would be near those values observed in the surrogates and $1 a b$ samples.

- The acoustic information would be suitable for two-dimensional tomography.

\section{What Did We Learn}

After careful analysis of the data from a single tank, 114-TX, the following conclusions were reached:

- Acoustic information can be transmitted between LOWs.

- Simulants are NOT good models of the acoustic properties of the in-tank wastes. (The sound velocity of $3000 \mathrm{~m} / \mathrm{sec}$. is far higher than anything observed in simulants)

- Relatively low noise, low frequency and matched transducers, are indicated.

- The best acoustic frequency to penetrate the salt cake is approximately $900 \mathrm{hz}$.

- The wastes in tank 114-TX appears solid over the entire twelve feet of interrogation. .

- Acoustic tools are appropriate to assess stratification of the waste volume.

A model of an underground storage tank was prepared using the "best" available acoustic properties known for the sludge, 7 iquid and salt cake phases. Acoustic "data" was synthesized using this model. These data were then entered into a tomographic analyzer, producing an image of the wastes' stratification. This demonstration confirmed the viability of the acoustic imaging in USTs. 


\section{WHC-EP-0870, Rev. 0 \\ Where Do He Go From Here}

The first step should be to repeated the 114-TX measurements, incorporating the knowledge obtained from the initial tests. This will confirm the conclusions reached during the preliminary tests, refine the measured values and provide an objective assessment of tomographic imaging.

Individuals who use methods and equipment dependant on acoustic properties of tank wastes in should be convened periodically to share information. This forum should focus on technical issues to assure that activities that utilize similar physics, use the best available information and avoid common pitfalls. It should be made clear that is NOT a forum to promote or challenge programs. The technical information may be chat7enged, and defended, on scientific basis.

A strategy and implementation plan should be developed to interrogate single shell tanks (SST) with acoustic equipment deployed in drill-string housing or penetrometer.

Additional tasks to consider include:

Select a candidate SST that contains salt cake, liquid and sludge and demonstrate acoustic imaging to detect and identify waste stratification.

Select a double shel1 tank (DST) and address measurements from the annulus to the in-tank transducers focussing on the sludges and Tiquids.

Assess alternative interrogation methods. 


\section{WHC-EP-0870, Rev. 0}

\section{Appendix A}

Roger Turpening, Zhen Zhu, Carol Caravana, Joseph Matarese, ERL, MIT, Walter Turpening EGI Acoustic Imaging of Underground Storage Tank Wastes

A Feasibility Study

\section{Final Report}

$6 / 95$ 


\title{
Acoustic Imaging of Underground Storage Tank Wastes
}

\author{
A Feasibility Study \\ Final Report
}

Roger Turpening, Zhenya Zhu, Carol Caravana, Joseph Matarese

Earth Resources Laboratory

Department of Earth, Atmospheric, and Planetary Sciences

Massachusetts Institute of Technology

Cambridge, Massachusetts 02142

Walter Turpening

Elohi Geophysical Inc.

Houston, Texas 77477 


\section{Table of Contents}

Background

Surrogates-General 1

Surrogates Used in This Study 2

Salt Cake

Aqueous Solutions

Sludge

Laboratory Measurement System 2

Procedure

Solids

3

Solutions and Sludge

Results

Salt Cake Surrogates and Aqueous Solutions of the Salt Cake

Surrogates

Sludge Surrogate

Seismic Measurements Inside Tank 114-TX

The Tank

Geometry

Acoustic Source

Acoustic Receivers

Recorder

In-Field Processing

Operations

Data

Interpretation

Tube Waves

Travel Times

Frequency Spectra

6

7

Imaging Possibilities

Model

Numerical Modeling

8

Imaging

8

Cross Well Logging and Cross Well Reflection 
Summary

Conclusions

Future Work

Acknowledgements

9

References

10

Appendix A

Appendix B 


\section{List of Figures}

Figure 1 Diagram of laboratory appratus for measuring acoustic velocities and attenuation

Figure 2 Plan view of tank 114-TX showing LOWs used in this study

Figure 3 Diagram displaying a priori knowledge of waste and geometry of survey

Figure 4 Response curve for hydrophones used in the survey

Figure 5 Acoustic data collected in the tank in receiver gather format, bottom hydrophone to hydrophone at 4.5 feet from bottom

Figure 6 Acoustic data collected in the tank in receiver gather format, hydrophone at 5.0 feet to hydrophone at 9.5 feet from bottom

Figure 7 Acoustic data collected in the tank in receiver gather format, hydrophone at 10.0 feet to hydrophone at 11.5 feet from bottom

Figure 8 Synthetic seismograms for a two layer model of waste showing reflections from salt cake/liquid interface and reflections from top of salt cake

Figure 9 Amplitude spectrum of data collected near the top of the survey

Figure 10 Model of waste and source/receiver geometry used in numerical imaging experiments

Figure 11 Model of waste, in terms of velocities, used in numerical imaging experiments

Figure 12 Travel times computed for acoustic first arrivals for a source at a depth of 17 feet

Figure 13 Tomographic image obtained using the computed first arrival travel times 


\section{Acoustic Imaging of Underground Storage Tank Wastes}

\section{A Feasibility Study}

\section{Final Report}

Roger Turpening, Zhenya Zhu, Carol Caravana, Joseph Matarese

Earth Resources Laboratory

Department of Earth, Atmospheric, and Planetary Sciences

Massachusetts Institute of Technology

Cambridge, Massachusetts 02142

Walter Turpening

Elohi Geophysical Inc.

Houston, Texas 77477

\section{Background}

The objectives for this underground storage tank (UST) imaging investigation are:

1) To assess the feasibility of using acoustic methods in UST wastes. If shown to be feasible, develop and assess imaging strategies.

2) To assess the validity of using chemical simulants for the development of acoustic methods and equipment.

\section{Surrogates-General}

The original chemical processes that generated the wastes that now exist in the tanks at Hanford are generally known well enough that surrogate materials can be created. Although the chemical nature of these substances is known it is not obvious that some of the mechanical properties, such as velocity, faithfully represent the mechanical properties of the real wastes. None-the-less given no other starting point one should measure the mechanical properties of some surrogates as a planning step before any data acquisition program is undertaken in the Hanford tanks.

Here it is the velocity and attenuation of the elastic waves in the surrogates that interest us. Laboratory methods for measuring these velocities on small samples are well established in the geophysical community. The Earth Resources 
Laboratory (ERL) has a laboratory capable of making elastic wave measurements on simple and complex samples.

\section{The Surrogates Used in This Study}

Salt Cake

Ames Laboratory at the University of lowa made the BY-104 simulant, as noted in Appendix A, based on a WHC recipe and shipped the salt cake samples to ERL. The main recipe, whose principal component is sodium nitrate, is given in the appendix along with the six intermediate stages of drying that resulted in six different dry, solid surrogates.

\section{Aqueous Solutions}

It was recognized that the wastes observed in various tanks are not all solid, dry wastes therefore an attempt was made to "liquefy" the surrogates. A portion of four of the surrogates (\#3, \#4A, \#5, and \#6) were ground up into fine powder and water was added. Two cases were tried, the first where an amount of water equal to $30 \%$ of the sample weight and another where the amount of water was equal to $50 \%$ of the sample weight. The compressional wave velocities were measured for each of these eight "solutions".

\section{Sludge}

Prof. Dennis Shelly of Texas Tech University provided us with a surrogate that is much closer in consistency to sludge. The compressional wave velocity and attenuation of these sludge surrogates was then measured in ERL lab. The appendix contains the recipe used by Prof. Shelly to make this simulant.

\section{Laboratory Measurement System}

Figure 1 shows a diagram for the system used to make the lab measurements of the surrogates. The top of the sample was planned smooth so that the receiver transducer could be attached. A pulse generator excited the compressional or shear wave transducer on the bottom of the can or beaker and the elastic wave passing through the sample was received by the transducer on the top of the sample. The received waveforms were displayed on an oscilloscope and recorded by a computer. The travel time was determined by picking the first arrival of the elastic wave. There is a time delay for the system and it includes the electric time delay of the transducer. the acoustic time delay of the transducer, and the time for the elastic wave to travel through the bottom of the container.

The elastic transducers are made by the Parametrics Co. (V103, compressional wave transducer, V153, shear wave transducer) They are 0.5 inches in diameter with $1 \mathrm{MHz}$. center frequency and can be used as both source and receiver. A special coupler, a shear wave coupler (SWC) was used for coupling the shear wave transducer to the sample 


\section{Procedure}

\section{Solids}

The thickness of the sample was measured along with the system time delay and the travel time of the compressional or shear wave. The velocity was then computed from these values.

The attenuation in a surrogate was measured by recording the amplitude of two different compressional wave arrivals after they have propagated over two different thicknesses. The attenuation factor, a, was calculated from

$$
a=\ln \left(A_{2} / A_{1}\right) /\left(L_{1}-L_{2}\right)
$$

A term common in studies of attenuation, the quality factor $Q p$ is calculated as follows:

$$
Q p=p f / a V p
$$

where $f$ is the frequency and $V p$ is the compressional wave velocity. We measured the amplitudes $A_{1}$ and $A_{2}$, and computed the attenuation coefficient, only on samples \#4A and \#5.

\section{Solutions and Sludge}

Measurements of the solutions of ground up salt cake in water and the sludge were conducted by placing the compressional wave transducers in the fluid samples. To measure the distance between the source and receiver the fluid was replaced with water and a travel time observation was noted.

\section{Results}

Salt Cake Surrogates and Aqueous Solutions of the Salt Cake Surrogates The compressional $(V p)$ and shear wave velocities (Vs) and the compressional wave attenuation $(Q p)$ of selected salt cake surrogates are given here. 
BY-104 from Ames Laboratory

\begin{tabular}{|c|c|c|c|c|c|}
\hline Sample & $\begin{array}{c}\text { Dry } \\
\text { Sample } \\
\text { Vp (m/sec) } \\
\text { (ft/sec) }\end{array}$ & $\begin{array}{c}\text { Dry } \\
\text { Sample } \\
\text { Vs (m/sec) } \\
\text { (ft/sec) }\end{array}$ & $\begin{array}{c}30 \% \text { Water } \\
\mathrm{Vp}(\mathrm{m} / \mathrm{sec}) \\
(\mathrm{ft} / \mathrm{sec})\end{array}$ & $\begin{array}{l}\mathbf{5 0 \%} \text { Water } \\
\mathrm{Vp}(\mathrm{m} / \mathrm{sec}) \\
(\mathrm{ft} / \mathrm{sec})\end{array}$ & $Q p$ \\
\hline$\# 1$ & $\begin{array}{l}2,330 \\
7,640\end{array}$ & $\begin{array}{l}1,360 \\
4,462\end{array}$ & & & \\
\hline$\# 3$ & $\begin{array}{l}1,990 \\
6,530\end{array}$ & $\begin{array}{l}1,100 \\
3,610\end{array}$ & $\begin{array}{l}2,060 \\
6,760\end{array}$ & $\begin{array}{l}1,710 \\
5,610\end{array}$ & \\
\hline$\# 4$ & $\begin{array}{l}1,890 \\
6,200\end{array}$ & $\begin{array}{l}1,150 \\
3,770\end{array}$ & & & \\
\hline$\# 4 A$ & $\begin{array}{l}2,220 \\
7,280\end{array}$ & $\begin{array}{l}1,330 \\
4,360\end{array}$ & $\begin{array}{l}2,140 \\
7,020\end{array}$ & $\begin{array}{l}1,890 \\
6,200\end{array}$ & 3.4 \\
\hline$\# 5$ & $\begin{array}{l}2,120 \\
6,960\end{array}$ & $\begin{array}{l}1,300 \\
4,265\end{array}$ & $\begin{array}{l}2,180 \\
7,150\end{array}$ & $\begin{array}{l}1,890 \\
6,200\end{array}$ & 1.7 \\
\hline \#6 & $\begin{array}{l}1,830 \\
6,000\end{array}$ & $\begin{array}{r}940 \\
3,080\end{array}$ & $\begin{array}{l}1,970 \\
6,460\end{array}$ & $\begin{array}{l}1,750 \\
5,740\end{array}$ & \\
\hline
\end{tabular}

Sludge Surrogate

The velocities and attenuation for the sludge simulant are given here along with the values for water for comparison purposes:

Immature BY-104 (Sludge) from Texas Tech University

\begin{tabular}{lcccc} 
Sample & frequency & $\begin{array}{c}\mathrm{Vp}(\mathrm{m} / \mathrm{sec}) \\
(\mathrm{ft} / \mathrm{sec})\end{array}$ & $\begin{array}{c}\text { alpha } \\
\text { (neper/m) } \\
\text { (neper/ft.) }\end{array}$ & Qp (1/neper) \\
\hline Water & $500,000 \mathrm{~Hz}$ & 1,480 & 4.2 & 300 \\
& & 4,860 & 1.3 & \\
Sludge & $500,000 \mathrm{~Hz}$. & 1,760 & 120 & 7.5 \\
& & 5,770 & 37 &
\end{tabular}

\section{Seismic Measurements Inside Tank 114-TX}

The above values for velocity and attenuation were used as guidelines during the preparations for field work inside one of the waste tanks at Hanford. As mentioned above it was recognized that there will be variations in seismic velocities and attenuation values from tank to tank as well as from the surrogates 
to the real waste materials therefore the parameters from these surrogates were not used for any precise planning.

The Tank

The tank selected by Westinghouse Hanford Co. personnel for this test was 114TX, a stabilized, single shell UST in the 200 West Tank Farm area. The tank characteristics are:

Total capacity

Total waste volume

Total liquid (included in total waste volume)

Salt cake depth

Interstitial liquid depth
750,000 gal. 535,000 gal. 15,000 gal.

$16.8 \mathrm{ft}$.

$6.26 \mathrm{ft}$.

The holes for this survey are:

Two fiber glass cased liquid observation wells (LOWs)

Four inch, O. D.

Separation $30 \mathrm{ft}$.

Each filled with water to a depth of $12 \mathrm{ft}$. for this survey

\section{Geometry}

The assumption that the bottom six feet of the salt cake would have liquid in the pores was central to the planning of the survey. It was expected that the coupling of the fiberglass casing to the wastes would be poor in the upper, dry waste and excellent in the lower region. Since the coupling of the LOW to the waste is a critical issue in the use of acoustic methods in the tanks we planned for half of the survey to be conducted in the dry waste region and half in the lower, moist wastes. Time and funding, mandated that the survey be completed in one day therefore a $24 \times 24$ data acquisition plan was designed (Figure 3). With a level spacing of 0.5 feet this plan allowed us to survey the lower 11.5 feet of the 17 feet of material in the tank. Since this was a feasibility study it was not intended that we examine the entire column of waste.

The LOWs were $30 \mathrm{ft}$. apart therefore the survey was not ideal for tomographic purposes. In order to achieve reasonable horizontal resolution it is necessary that the survey be "square" in shape or better yet a "tall rectangle". This means that the height of the survey should be at least equal to the distance between the boreholes or greater. In this study we were interested only in the fundamental questions about acoustic propagation in real waste materiais not issues of imaging.

\section{Acoustic Source}

The source was constructed of six (6) piezoelectric, cylindrical bender crystals each two inches long and 2.5 inches in diameter (OD). This made the completed source, with end caps and wireline feed-through, eighteen inches long. The amplifier driving the source was flat in output, 1,500 watts, from $40 \mathrm{~Hz}$ to 40,000 $\mathrm{Hz}$. The source could be operated in a pulsed manner or swept. A polynomial 
waveform synthesizer generated a 0.7 second sweep from $300 \mathrm{~Hz}$ to $3,000 \mathrm{~Hz}$. and sixteen sweeps were stacked to yield one record.

Acoustic Receivers

Three hydrophones placed two feet apart on a single wireline were used as receivers. They had an outside diameter of $17 / 8$ inch. The response of the hydrophones is given in Figure 4.

Recorder

A Geometrics R-12 recording system was used. The sampling rate selected for this survey was 16,000 samples per second per channel. The uncorrelated sweeps were stacked on this system.

In-Field Processing

A Macintosh Power Mac 7100 was used for in-field quality control. Using Parallel Geosciences Seismic software we were able to examine the data in the field. In particular the cross correlation was performed here.

\section{Operations}

The LOWs were filled with water to a depth of twelve feet, to provide the coupling for the source and receivers to the casing. Experience has shown that the survey proceeds more rapidly if the source, not a receiver, is moved most often during cross well data acquisition. Moving the receivers generates noise in that particular well. After a short period of time the noise dies away but time is wasted waiting for that decay. Therefore it is most expedient to fix the receivers and move the source over its twenty four levels then move the receivers a small increment, 0.5 feet in this survey, and repeat the motion of the source.

Permanent marks painted on each of the cables at 0.5 foot intervals made it easy to accurately repeat the operation.

\section{Data}

Figures 5,6 , and 7 display the data in receiver gather format. A receiver gather is a plot of the waveforms seen at one receiver for all positions of the source. Remember that the weils are thirty feet apart while the height of the survey is only 11.5 feet. Therefore all of the ray paths are essentially the same length and the resulting travel times are similar.

\section{Interpretation}

A receiver gather is a plot of data from all source positions as seen from a single receiver (hydrophone in this case) position. Now since the sources are thirty feet away from any given hydrophone and range over only 11.5 feet it is clear that the source-to-hydrophone distances are all nearly identical. Therefore very little travel time variations are to be expected in the data.

\section{Tube Waves}

The strong waves that are obvious late in the records (times greater than 0.006 sec.) are all tube waves of various kinds. These waves propagate up and down the water filled LOWs (see for example Cheng and Toksöz, 1982). Tube waves are easily generated in the source LOW every time the source is fired and they 
are generated at a later time in the receiver LOW by several different means. A rigorous examination of the tube waves here is beyond the scope of this feasibility study but it is important to note that if one wishes to use reflected acoustic energy for imaging inside a tank they will have to be addressed.

Travel Times

Ahead of the tube waves at a time of approximately 0.0025 to 0.003 seconds is a low frequency, weak arrival that persists over all of the receiver gathers. This is the first arriving compressional wave. One hydrophone (bottom through $1.5 \mathrm{ft}$., and $6.0 \mathrm{ft}$. through $7.5 \mathrm{ft}$.) was noisier than the other two therefore the signal to noise ratio is poorer on those traces. Some variation in the travel time is seen for the gathers around $2.0 \mathrm{ft}$. to $3.5 \mathrm{ft}$. and the event seems to split into two events in that region. Indeed forward modeling (Figure 8 ) indicates that this double arrival is produced by the direct arrival and a reflection from the bottom of the tank. If the signal to noise ratio were better we might see this double arrival at other levels in the data.

This acoustic wave data is too poor to make rigorous statements about the travel times. However, for this purposes of this feasibility study one can say that a travel time of approximately 0.003 seconds was observed between the two LOWs. At the bottom of the survey one could argue that head waves (energy critically refracted along the concrete) through the concrete could give a false travel time, therefore those gathers have been ignored in the above statement. All of the upper gathers (hydrophones at $10.0 \mathrm{ft}$. through $11.5 \mathrm{ft}$.) yield a travel time of approximately 0.003 seconds and they are probably not contaminated by head waves.

The time of 0.003 seconds represents a velocity of approximately $10,000 \mathrm{ft} . / \mathrm{sec}$. or approximately $3,000 \mathrm{~m} / \mathrm{sec}$ for the wastes between these two LOWs. This velocity is faster than any observed in our laboratory measurements or the measurements of other investigators.

\section{Frequency Spectra}

Figure 9 is the spectrum of trace 22 from the upper most receiver gather (11.5 ft.). The energy peak at $900 \mathrm{~Hz}$ is probably associated with the strong tube waves present there. However if we assume that the double arrival is the correct representation for the first arriving acoustic wave then a simple measurement of the period of those waves also yields a frequency of approximately $900 \mathrm{~Hz}$. The double arrivals seen in the $11.0 \mathrm{ft}$. gather were used to estimate the frequency of the first arrival.

\section{Imaging Possibilities}

This feasibility study has taught us the approximate velocity for wastes in tank 114-TX and given us an estimate for the frequency band of interest for the first arriving acoustic waves. We knew at the outset that tomographic imaging could not be used here due to the survey geometry--too little aperture on each side compared to the distance between the LOWs. However a survey geometry ideal for tomographic imaging can be achieved in any tank with any depth of wastes by properly placing the source and receiver holes. 
In addition cross well reflection can be used in the future in all of the above survey geometries along with tomography. Cross well reflection can also be used in those cases, such as tank 114-TX, where tomographic work is inappropriate. To do that one must work to remove the tube waves and that problem is being attacked currently in the hydrocarbon industry in the name of single well imaging.

However, we can examine the benefits of tomographic imaging of the wastes now by means of numerical modeling. First we hypothesize a structure, stratigraphy, for wastes in a tank. Then we compute the seismic wave propagation that would occur in those wastes for sources and receivers in a given geometry. The resulting waveforms, ("synthetics") can then be used as input to a tomographic imaging algorithm. In this study we choose to use a nonlinear, travel time tomography algorithm (Matarese, 1993) that requires only the arrival time of the first arriving energy. However, other more powerful imaging algorithms exist such as those that require the amplitude of the first arriving energy (Thompson, 1994) as well as its travel time.

\section{Model}

The model chosen for this numerical exercise is given in Figure 10 with its color representation given Figure 11 This is a realistic model given our knowledge of the velocities of some surrogates and our rough estimates of the velocities in tank 114-TX. In this model the wastes fill a tank to a depth of thirty feet and the holes are also thirty feet apart.

\section{Numerical Modeling}

A finite difference technique was chosen here as the numerical technique for computation of the acoustic wave field. This technique was chosen here because it is mathematically dissimilar to the technique, ray tracing, that is central to tomographic imaging algorithms. In this manner we avoid the criticism, justified, of inverting a wave field with the same method that was used to generate the wave field. Figure 12 displays an example of the output of the finite difference algorithm for a source at a depth of seventeen feet.

\section{Imaging}

The entire suite of 4,761 travel times (69 sources and 69 receivers) were then used as input to Matarese's non-linear travel time algorithm. Figure 13 is the image of the wastes achieved with a run time of one half hour on a massively parallel computer (nCUBE using 64 nodes). The artifacts due to poor ray coverage in the corners of the image are evident here. These artifacts along with the features seen in the low velocity water layer are due to the geometry of cross well methods and are not the fault of the fundamental technique.

\section{Cross Well Logging and Cross Well Reflection}

When the geometry of the holes and waste depth is not optimum for tomographic imaging one can still obtain some information about the waste from cross well logging and cross well reflection methods. These techniques, as their name implies, use appropriate subsets of a full tomographic data set. In the case of 
cross well logging one uses data from sources and receivers that are at the same depth. Although it is recognized that the acoustic energy did not propagate "straight across" from source to receiver one does get a crude estimate of the velocity of the intervening waste material. The data collected in this feasibility study is essentially cross well logging data. Care must be taken in cross well logging work to recognize known arrivals of little interest, such as head waves through the concrete, in this case.

In the case of cross well reflection one uses the reflections such as those seen in Figure 8 instead of the direct arrivals. Given the velocities of the materials the data sections themselves can be reorganized (migrated) to represent the interfaces just as is done in surface reflection work.

\section{Summary}

This investigation examined the velocity of surrogates, both salt cake and sludge surrogates. In addition we collected seismic cross well data in a real tank (114$T X$ ) on the Hanford Reservation. Lastly, drawing on the knowledge of the simulants and the estimates of the velocities of the waste in tank 114-TX we generated a hypothetical model of waste in a tank and showed that non-linear travel time tomographic imaging would faithfully image that stratigraphy.

\section{Conclusions}

The primary conclusions to be drawn from this feasibility study are the following:

Seismic cross well tomographic techniques can be used between holes (LOWs, core holes, etc. ) inside Hanford waste tanks

The frequency of the first arriving acoustic wave is approximately 1 kilohertz

The salt cake in tank 114-TX has a higher velocity than any of the surrogates we measured in the laboratory.

\section{Future Work}

Future work should focus on the following topics:

Increase the power of the source (longer sweeps, stack more sweeps, more crystals etc).

Perform a second, more extensive survey in tank 114-TX

\section{Acknowledgments}

This work was supported by the Hanford Operations and Engineering Contractor under Department of Energy contract DE-AC06-87RL10930. We wish to recognize the past support of the Office of Basic Energy Sciences (Geosciences Research Program) which made thenon-linear traveltime tomographic imaging possible. 


\section{References}

Cheng, C. H. and M. N. Toksöz, (1982), Generation, propagation, and analysis of tube waves in a borehole, Transactions, Society of Professional Well Log Analysts, 23rd Annual Logging Symposium Corpus Christi, Texas,

Matarese, J. R. (1993), Nonlinear Traveltime Tomography, Ph.D. Thesis, Department of Earth, Atmospheric, and Planetary Sciences, Massachusetts Institute of Technology, Cambridge, Massachusetts

Thompson, D. R. (1993), Nonlinear Waveform Tomography: Theory and Application to Crosshole Seismic Data, Ph. D. Thesis, Department of Earth, Atmospheric, and Planetary Sciences, Massachusetts Institute of Technology, Cambridge, Massachusetts 


\section{Appendix A}

\section{Salt Cake Surrogate}

The salt cake surrogate was provided by Ames Laboratory

The simulant created was modeled after the modified saltcake simulant 104-BY, originally reproduced by Ted Hohl at Westinghouse Hanford Company. The recipe that we used is shown in Table 1.

\section{Table 1:}

104-BY Modified Simulant Recipe

$\begin{array}{ll}\text { Compound } & \text { Weight \% } \\ \text { sodium nitrate } & 81.8 \\ \text { sodium aluminate } & 7.5 \\ \text { sodium hydroxide } & 1.7 \\ \text { sodium metasilicate } & 1.5 \\ \text { ferric nitrate } & 1.0 \\ \text { sodium phosphate } & 0.7 \\ \text { calcium nitrate } & 0.4 \\ \text { magnesium nitrate } & 0.2 \\ \text { manganese (II) nitrate } & 0.2 \\ \text { water } & \text { approx.5 }\end{array}$

Ted Hohl also used sodium aluminate solution and manganese (II) nitrate solution to supply the trace quantities of these chemicals shown in Table 1. Since the acquisition of these solutions was not possible within our limited time frame, and since concentrations are quite small we started without them. Using some numbers given to us by Ted Hohl we figured that approximately $0.472 \mathrm{~kg}$ of sodium nitrate was used per liter of final solution. We planned on mixing approximately 4 liters of solution: Ignoring sodium alumininate and manganese (II) nitrate the amount of each substance used is listed in Table 2.

Table 2:

Amount of Compounds in Solution

$\begin{array}{ll}\text { Compound } & \text { Amount, } \mathbf{g} \\ \text { sodium nitrate } & 1887 \\ \text { sodium hydroxide } & 39.2 \\ \text { sodium metasilicate } & 34.6 \\ \text { ferric nitrate } & 23 \\ \text { sodium phosphate } & 16.1 \\ \text { calcium nitrate } & 09.2 \\ \text { magnesium nitrate } & 04.6\end{array}$


All the compounds were then mixed into a $4 \mathrm{~L}$ container with water and stirred. The mixture was rust colored and was mostly liquid with just small amounts of solids mixed in. The solution settled into two distinct layers. The first layer was clear and took up about $4 / 5$ of the $4 \mathrm{~L}$ beaker. The remaining $1 / 5$ was a cloudy rust colored substance on the bottom of the container. The solution was then stirred again to get an even distribution and then poured into an approximately $32 \mathrm{Oz}$. can. From there the can was placed in a $150^{\circ} \mathrm{C}$ oven. The liquid began evaporating and white crystals began forming on the inside of the can. The crystals were periodically scraped off the inside of the can and mixed back into the solution. The simulant finally reached a point where it became fairly thick and it no longer formed the white crystals on the side of the can. At about this point the simulant was separating into a solid white layer on top and a light brown layer undemeath. It then started to harden and a white powdery top formed. The entire drying time took approximately 58 hours. This sample was labeled \#1.

Since the first attempt at drying the simulant appeared to be successful we started two more batches. We also started another two in which we poured off the clear liquid forming on the top into separate containers hoping to speed up drying time. The liquid that came off the top in those two attempts was also put into the oven to be dried. The clear liquid began forming white crystals on the insides of the cans, it also formed crystals in the solution itself that looked liked crushed ice in water. The samples that had the clear liquid poured off do not-seem to harden as quickly as the original sample, \#1. They all finally dried and all formed a white powdery top.

Below is a list of what the 6 samples we sent you are.

\#1. The original first sample that was dried.

\#3. Just the solid that settled to the bottom with just a trace of the clear liquid on top. This sample was tried to see if a larger concentration of the solids on the bottom could be made.

\#4. $\quad$ The clear liquid that was poured off the top of sample \#3.

\#4A. The clear liquid that was poured off of sample \#6.

\#5. The same as \#1 except in a glass beaker so that the layering that occurs could be observed.

\#6. The same as \#3 except also in a glass beaker to obsenved layering.

All the samples that have been made were made to come as close as possible to the simulant at Hanford by Ted Hohl. None of the samples have had any testing done by anyone at lowa State. If you need any more saltcake simulant we have approximately enough solution to make about $300 \mathrm{ml}$ of the final simulant. We also can mix up more solution if necessary. The type of container that you prefer would also be helpful, we weren't sure if the simulant would be easier to remove from the glass beaker or the can so we made both. Please get 
back to either of us by e-mail or by calling $515-294-7338$ if you have any questions. 


\section{Appendix B \\ Immature Salt Cake Surrogate (Sludge Surrogate)}

The sludge surrogate was provided by Prof. Dennis Shelly of Texas Technology University in Lubbock, Texas.

Method for the Preparation of Westinghouse-Hanford BY-104 SST Immature Saltcake.

This method is based on the information provided by $S$. Eberlein on 8/12/93. See references 1 and 2 for background information. The 1-2 months of heating at $250 \mathrm{C}$ was determined unnecessary when considering that saltcake would likely be slurred prior to optical rheometry testing. Elimination of this heating/curing step greatly simplifies the procedure. The following describes a homogeneous precipitation method for the preparation of the BY-104 SST saltcake. Several batches have been prepared with this method. Contact the author if there are any questions.

\section{Apparatus}

Heating jacket for $3 \mathrm{~L}$ flask

Stirrer/mixer allowing continuous adjustment of speed and monitoring of torque

Balance (top loading)

\section{Glassware}

$3 \mathrm{~L}$ boiling flask or round bottom flask

two $1 \mathrm{~L}$ beakers

$10 \mathrm{ml}$ transfer pipette

\section{Chemicals}

Sodium nitrate $(1008.2 \mathrm{~g})$

Aluminum nitrate nonahydrate $(594.9 \mathrm{~g})$

Iron (III) nitrate nonahydrate $(28.4 \mathrm{~g})$

Calcium nitrate tetrahydrate $(9.67 \mathrm{~g})$

Sodium metasilicate pentahydrate $(43.9 \mathrm{~g})$

Magnesium nitrate hexahydrate $(6.97 \mathrm{~g})$

Manganese (II) nitrate hexahydrate $(7.13 \mathrm{~g}$ or $14.26 \mathrm{~g}$ of $50 \%$ solution)

Sodium phosphate, tribasic dodecahydrate (26.1g)

Sodium hydroxide pellets $(262.1 \mathrm{~g})$

Distilled water 


\section{Procedure}

1. Add the sodium nitrate to $500 \mathrm{~mL}$ of water in a $1 \mathrm{~L}$ beaker. Stir vigorously. After obtaining a reasonably stable suspension, transfer this to a $3 \mathrm{~L}$ boiling flask and mount in a heating jacket. Adjust the temperature to near boiling. 2. Add the next 5 ingredients to $300 \mathrm{~mL}$ of water, with constant stirring. When the sodium nitrate solution has warmed to near boiling (40 on rheostat), add this solution carefully to the heated flask.

3. Add the sodium hydroxide to $300 \mathrm{~mL}$ of water. Stir continuously. When nearly dissolved add sodium phosphate. Sonicate, if necessary, to promote dissolution. Dissolution is not complete with this material. Stir periodically and wash the sides of the beaker with distilled water.

4. Stir the reddish-brown liquid in the $3 \mathrm{~mL}$ flask, at $250 \mathrm{rpm}$ and near boiling (40 on rheostat), for at least $24 \mathrm{hr}$.

5. Begin to add the sodium phosphate/sodium hydroxide liquor in 10 to $15 \mathrm{~mL}$ increments, again with continuous stirring. Do not add more than $100 \mathrm{~mL}$ in 24 hr. Increase temperature to just above boiling point ( 45 on meostat). Replace any lost water to keep the flask at the $2 L$ volume mark and the mixer's torque at 21 oz.in.@ 250 rpm. Momentarily increase the stirring rate, as necessary, to achieve a free-flowing fluid.

6. When all the sodium phosphate/sodium hydroxide liquor has been added increase the temperature (50 on rheostat) and stirring rate (350 rpm) to maintain a homogeneous fluid. Add $500 \mathrm{~mL}$ of water to the remaining undissolved basic solids and add this slurry as in step 5 above. Liberally add water to keep the reacting fluids as homogeneous as possible. Note the formation of white scale deposits on the inside of the boiling flask. When this happens add more water to achieve the maximum liquid volume, $-3 \mathrm{~L}$. Frequently inspect the mixture and add water as necessary to prevent further precipitation.

7. When the remainder of the basic solution has been added increase the stirring rate to $400 \mathrm{rpm}$ and frequently inspect the suspension for deposits. After the volume is reduced to $2.5 \mathrm{~L}$, disconnect and remove the stirrer. With the flask still in the heating mantle, swirl the contents and attempt to dislodge the deposits using the stirrer rod. Pour the brown suspension into a 3 or $4 \mathrm{~L}$ beaker and place on hot plate. Set the temperature to medium (position 5). Replace the stirrer and set to $400 \mathrm{rpm}$. Carefully monitor the liquid volume and the formation of scale deposits. When the suspension volume has been reduced to about $1 \mathrm{~L}$ and the mixer's torque has reached 30 oz.in. @400 rpm, stop the mixer and transfer the suspension to storage containers.

8. The final suspension is stable at room temperature if stored in a polyethylene jar, tightly capped. Small samples have been removed, ground in a mortar and pestle and distributed for analysis. Care should be exercised when working with the caustic material. Despite the presence of nitrates, the final suspension does not present any safety hazard. 


\section{References}

1. Jones, Colton \& Bloom, Hanford SST Waste Preliminary Pretreatment Testing of Simulated Waste, exerted by S. Eberlein, 8/12/93.

2. Feed composition for synthetic BY-104 Saltcake: Spreadsheet Recipes, S. Eberiein, 8/12/93.

Author: D.C. Shelly

Date: $3 / 3 / 95$

Revision Number :2 


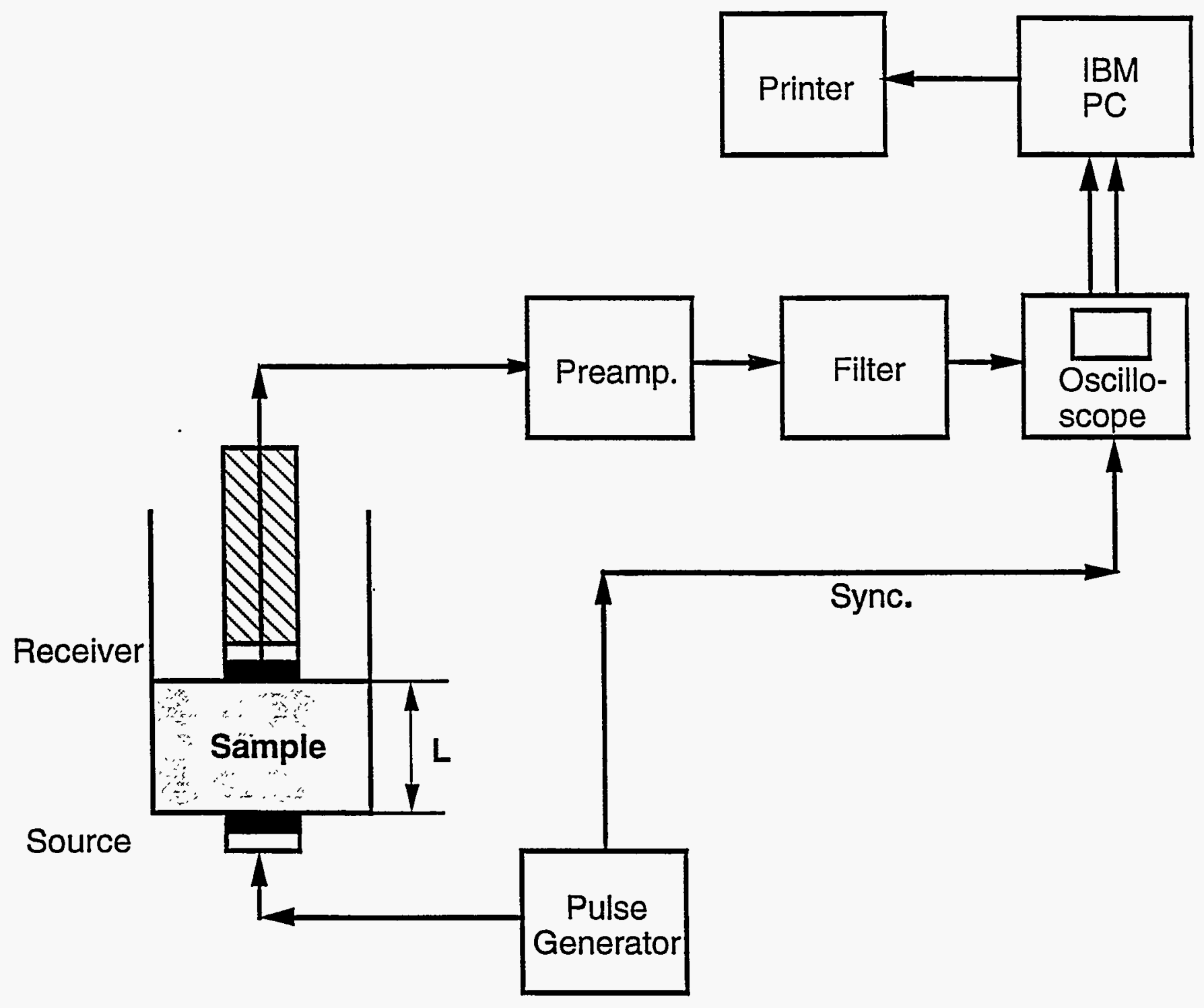

Figure 1. A diagram of the lab apparatus used to measure $P$ and $S$ velocities of samples. 


\section{TANK 241-TX-114}

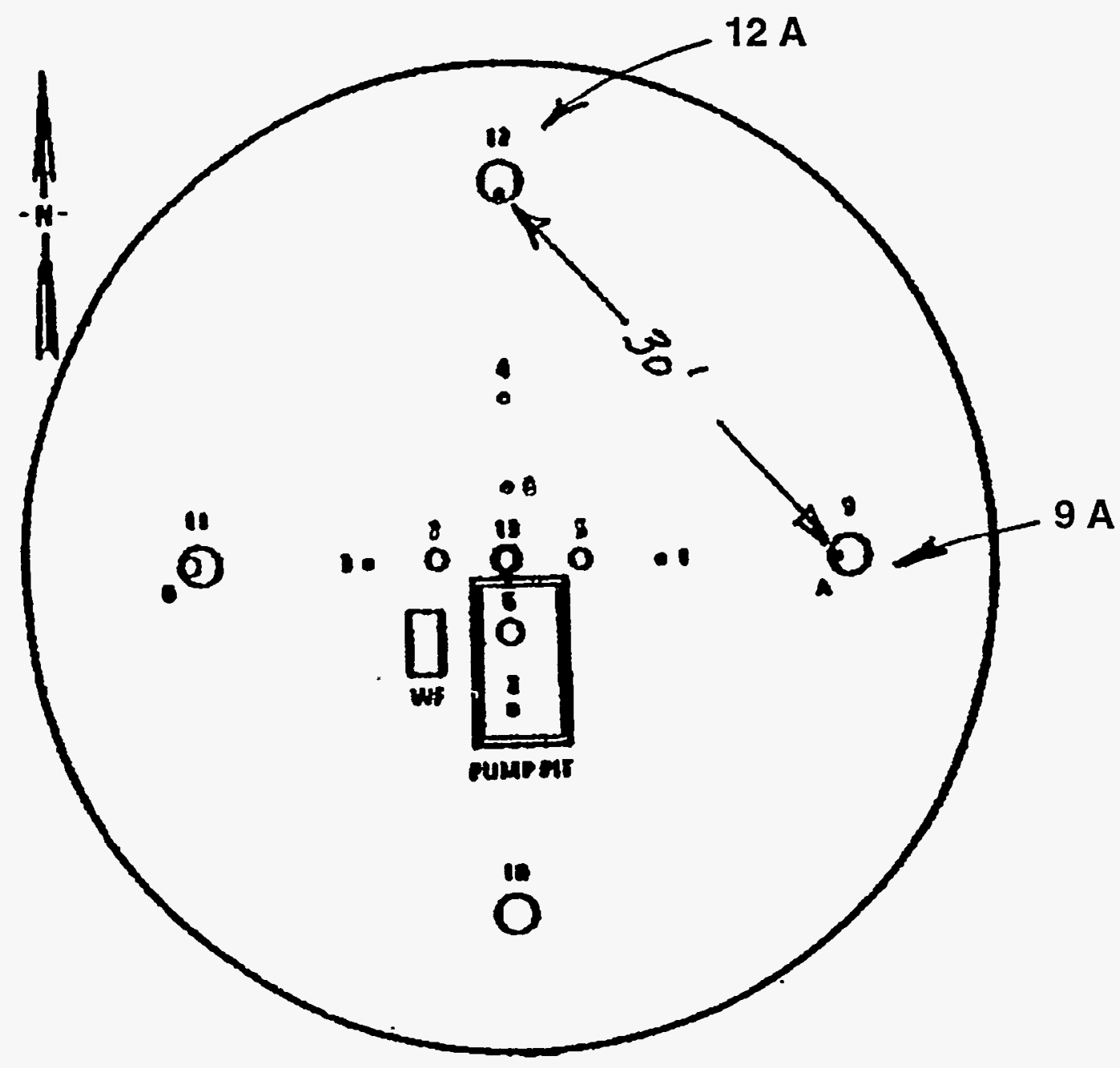

LOW \# Diameter Elevation Description

$\begin{array}{cccc}9 \mathrm{~A} & 4^{\prime \prime} & 670.32 & \text { Prototype Fiber LOW } \\ 12 \mathrm{~A} & 4^{\prime \prime} & 671.73 & \text { Prototype Fiber LOW, BM }\end{array}$

Figure 2. A plan view of the Hanford tank which was entered for the acoustic cross-well data aquisition. The liquid observation wells, $9 \mathrm{~A}$ and $12 \mathrm{~A}$, are 30 feet apart. 


\section{TANK $114-$ TX}

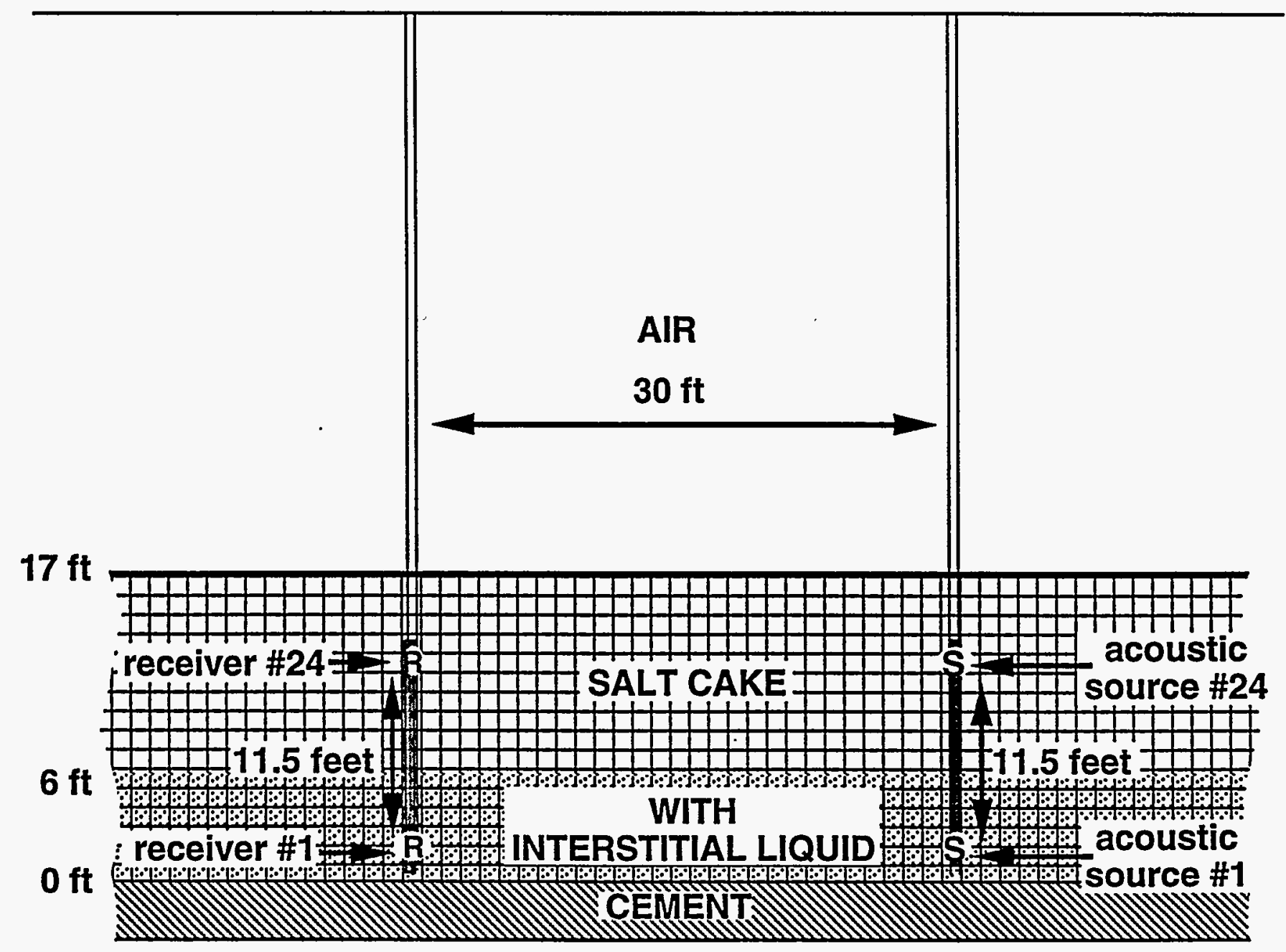

Figure 3. The cross-well survey geometry and information assumed before the data collection in tank 114-TX. A total of 24 sources and 24 receivers were used, giving an aperature of 11.5 feet. 


\section{Hydrophone Amplitude Response}

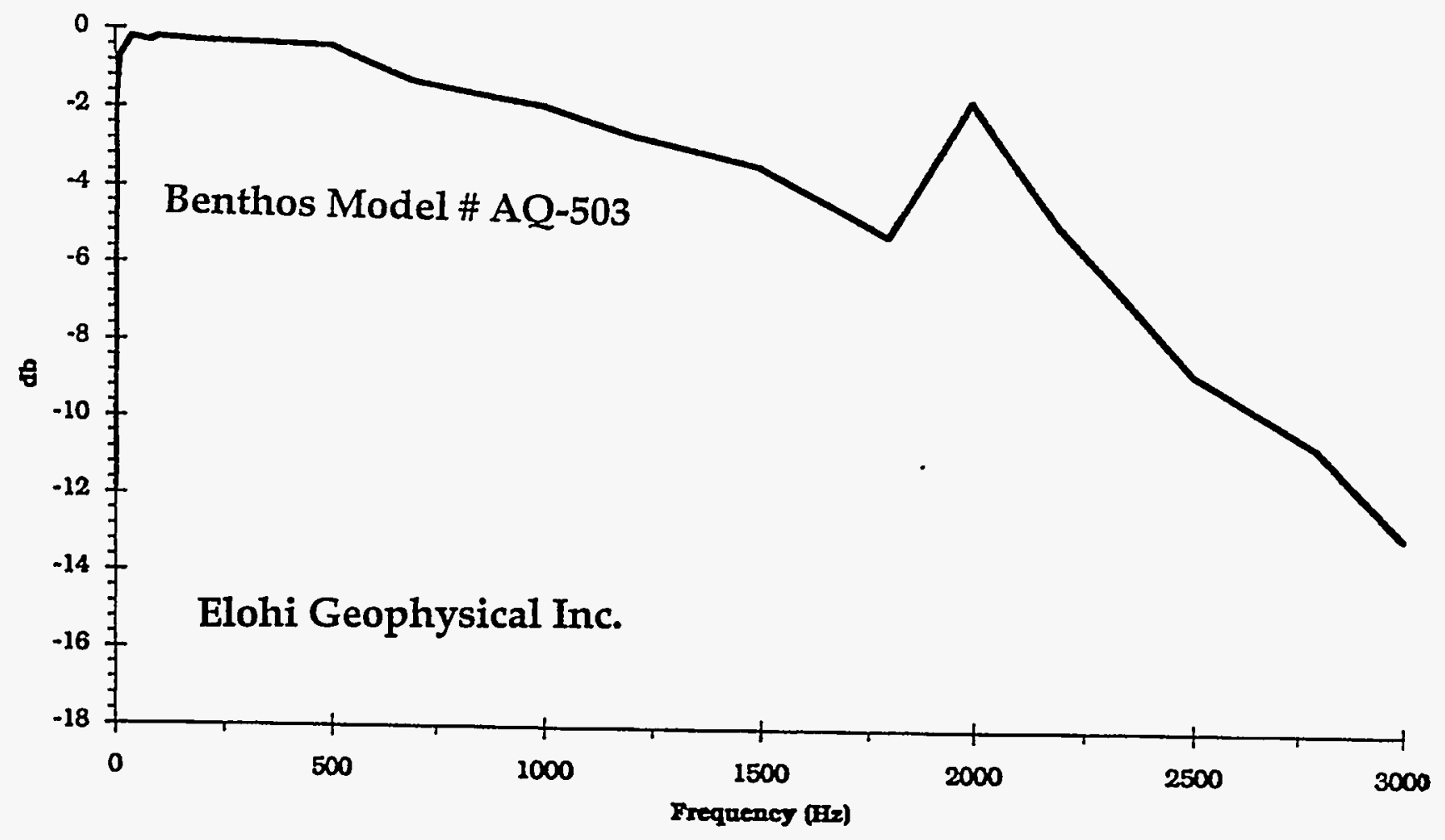

Figure 4. The amplitude response of the hydrophones used in the acoustic cross-well data aquisition. 


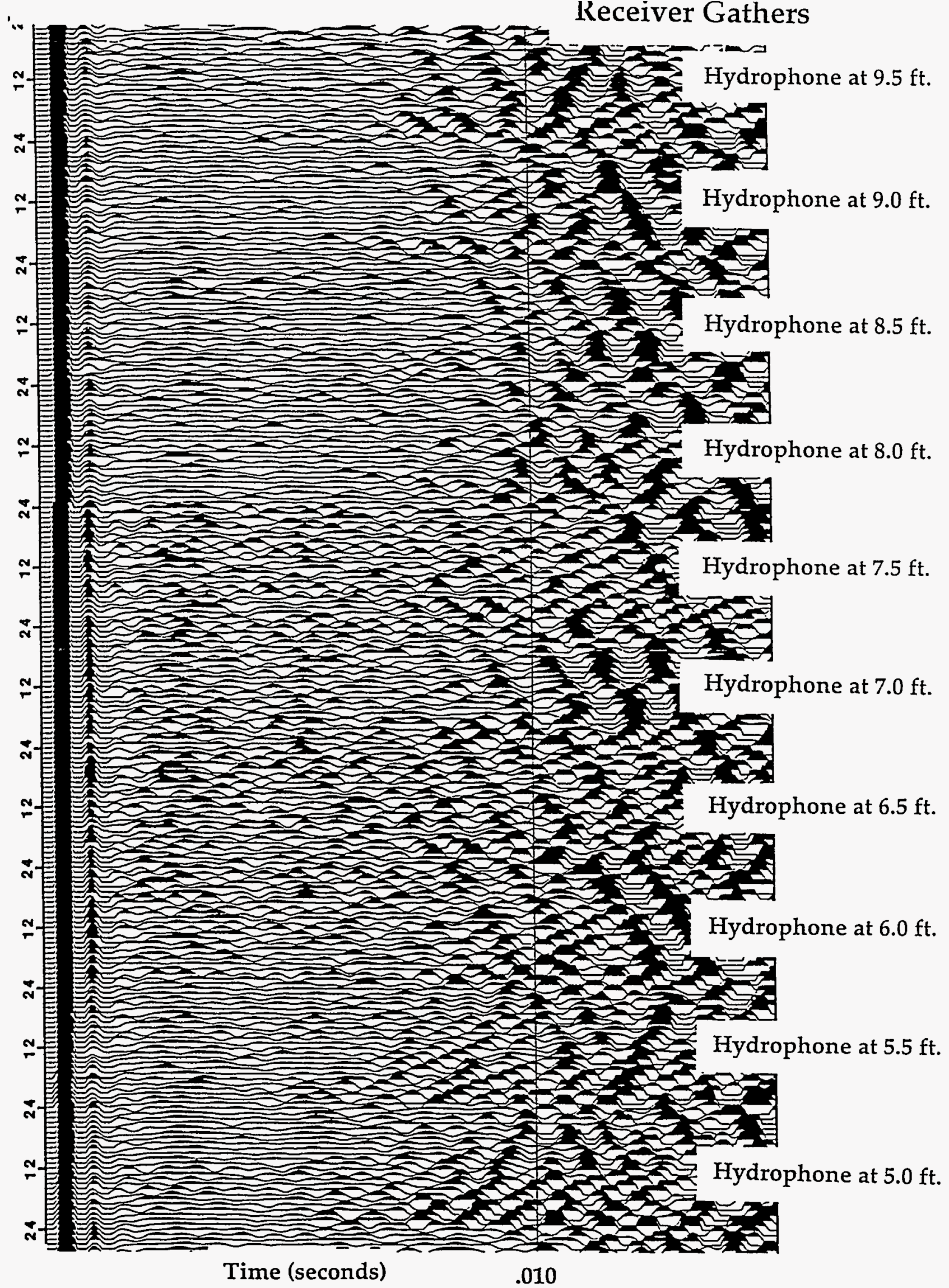

Figure 6. Acoustic data presented in "receiver gather" format. The position of each hydrophone is indicated. Associated with each hydrophone position are 24 traces representing the 24 positions occupied by the source in the opposite LOW. The strong, diagonal, events seen after approximately 0.005 seconds are tube waves propagating in the receiver LOW. The direct acoustic wave is the weak, low frequency, vertical event seen at approximately 0.003 seconds on all hydrophones for all source positions. Note that for the hydrophone positions at 8.0, 8.5, 9.0, 9.5 feet the direct arrival appears to be split into two, parallel arrivals. Compare these with the similar events seen in Figure 8. 


\section{Receiver Gathers}

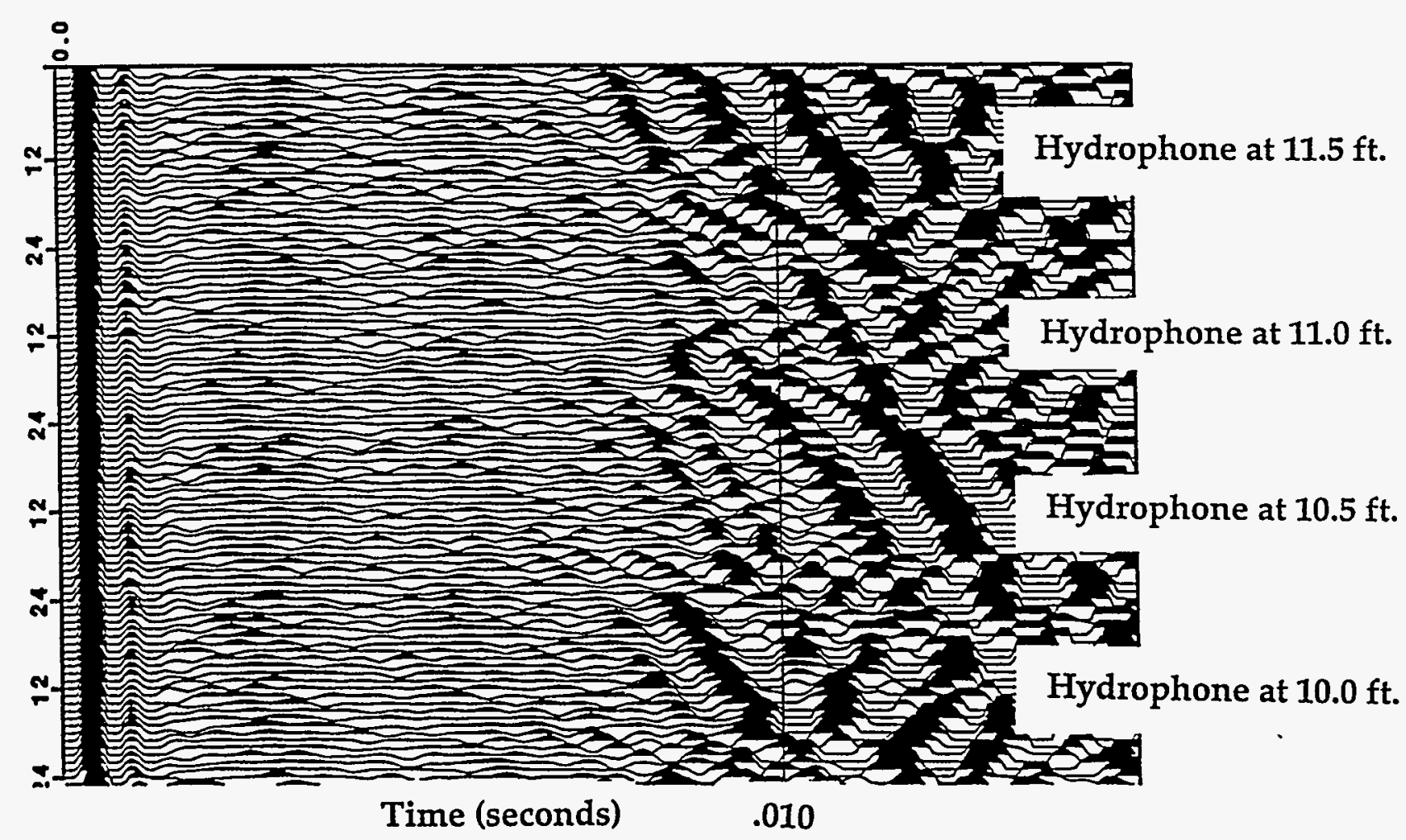

Figure 7. Acoustic data presented in "receiver gather" format.. The position of each hydrophone is indicated. Associated with each hydrophone position are 24 traces representing the 24 positions occupied by the source in the opposite LOW. The strong, diagonal events seen after approximately 0.005 seconds are tube waves propagating in the receiver LOW. The direct acoustic wave is the weak, low frequency, vertical event seen at approximately 0.003 seconds on all hydrophones for all source positions. Note that for the hydrophone position at 11.0 feet the direct arrival appears to be split into two, parallel arrivals. Compare these with the similar events seen in Figure 8. 

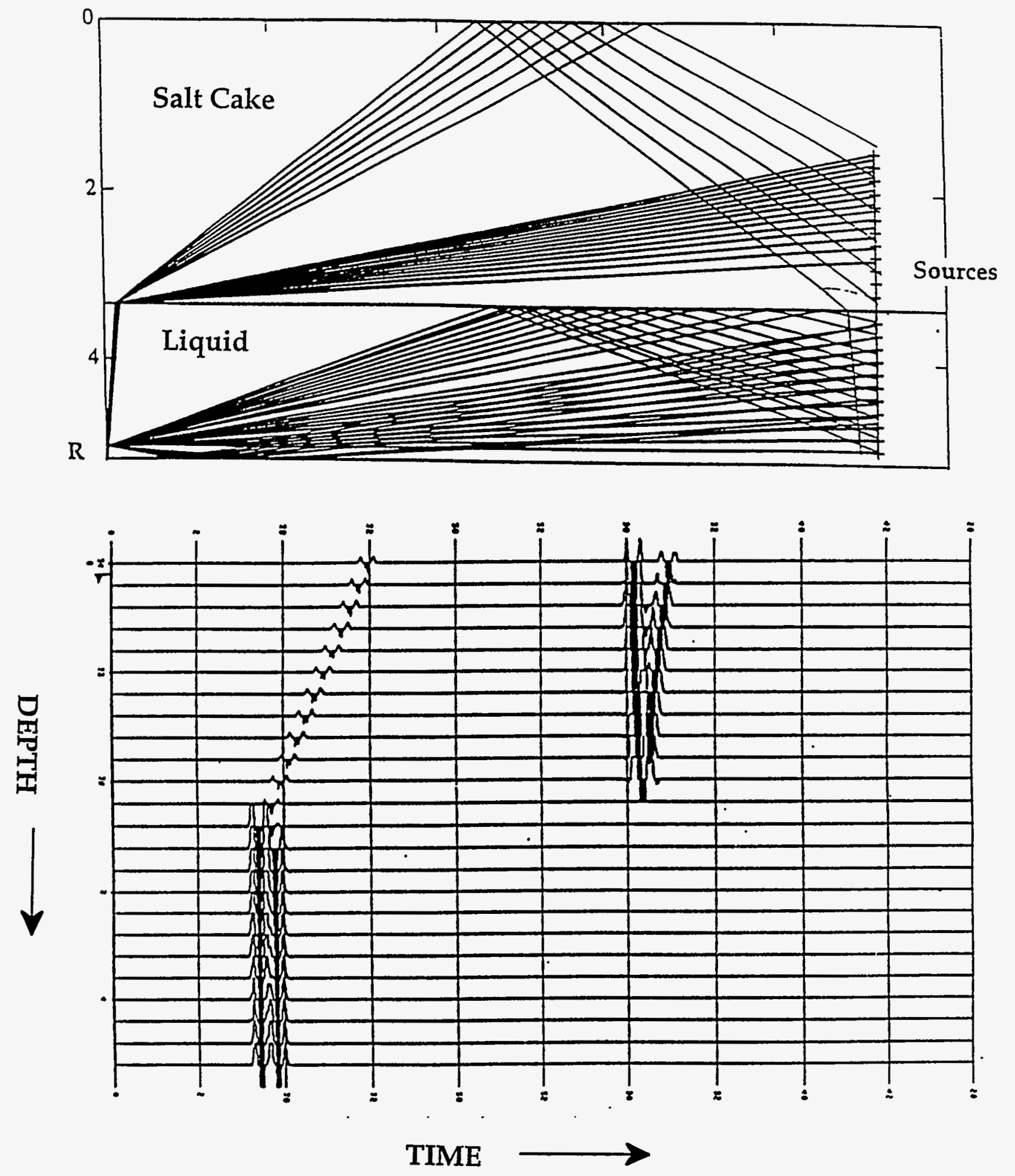

Figure 8. Synthetic seismograms derived for a two layer (salt cake over a liquid) model of wastes with a ray tracing algorithm. The purpose of this figure is to show that under certain conditions, such as the interface shown here, the first acoustic arrival can, in fact, be two closely spaced arrivals as seen in the data in Figures 6 and 7 . 


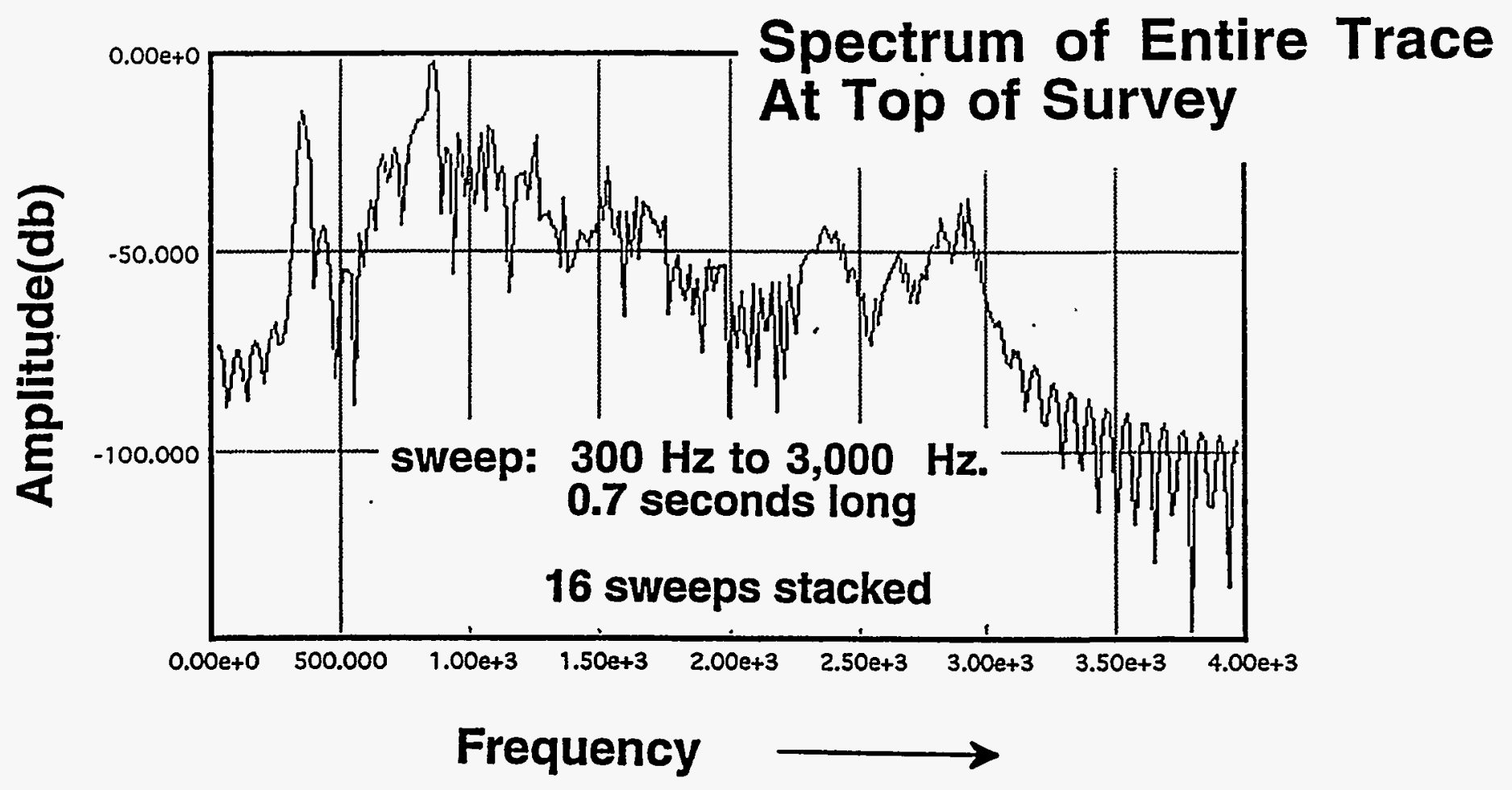

Figure 9. The amplitude spectrum of a trace where the source and the receiver were at the top of the survey, at a separation of 30 feet. 


\section{WASTE MODEL \#1 for NUMERICAL IMAGING EXPERIMENTS}

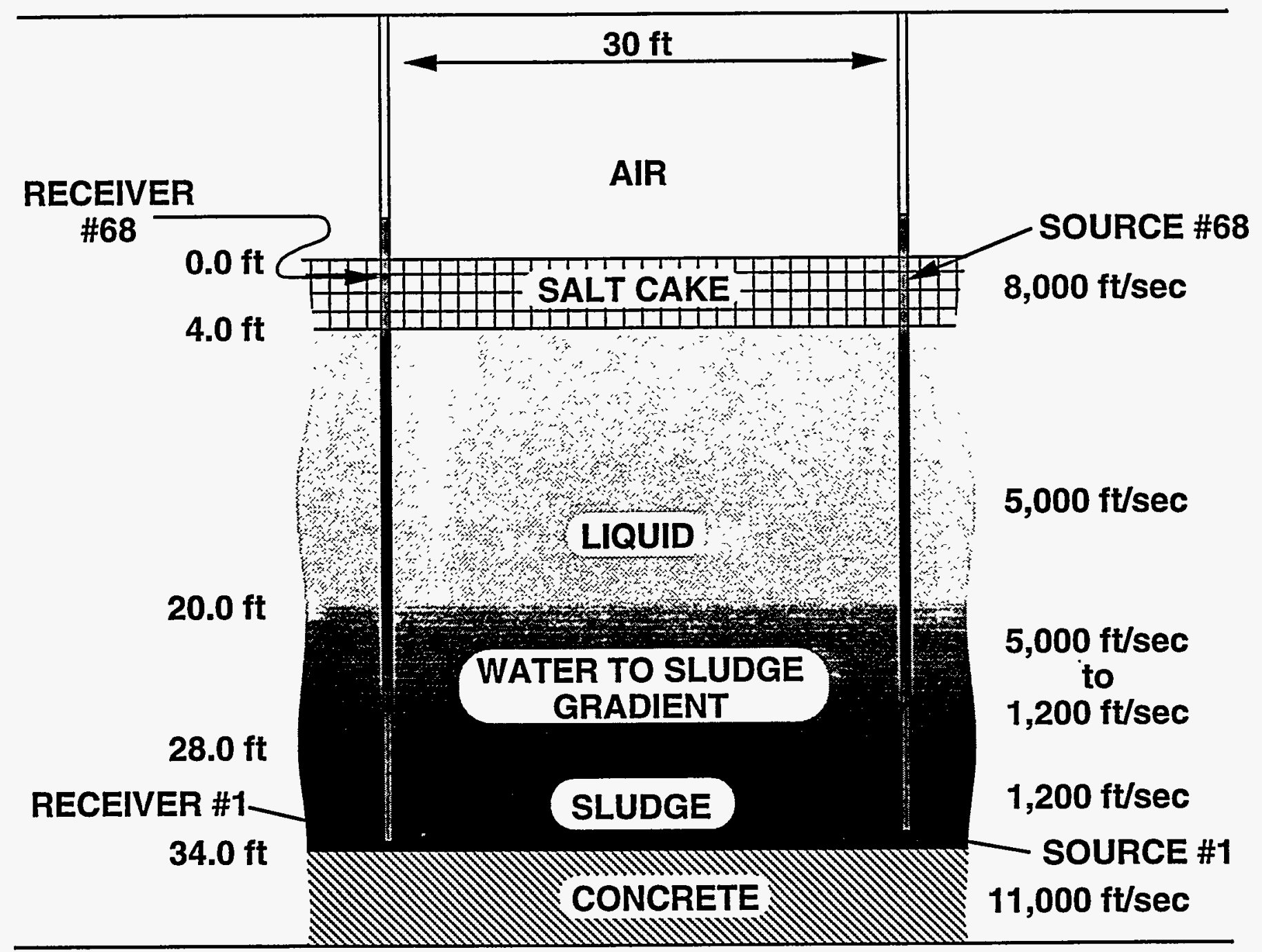

Figure 10. Model parameters used for the forward model, which was then inverted for the tomographic image. 


\section{HANFORD WASTE MODEL \#1 VELOCITY MODEL}
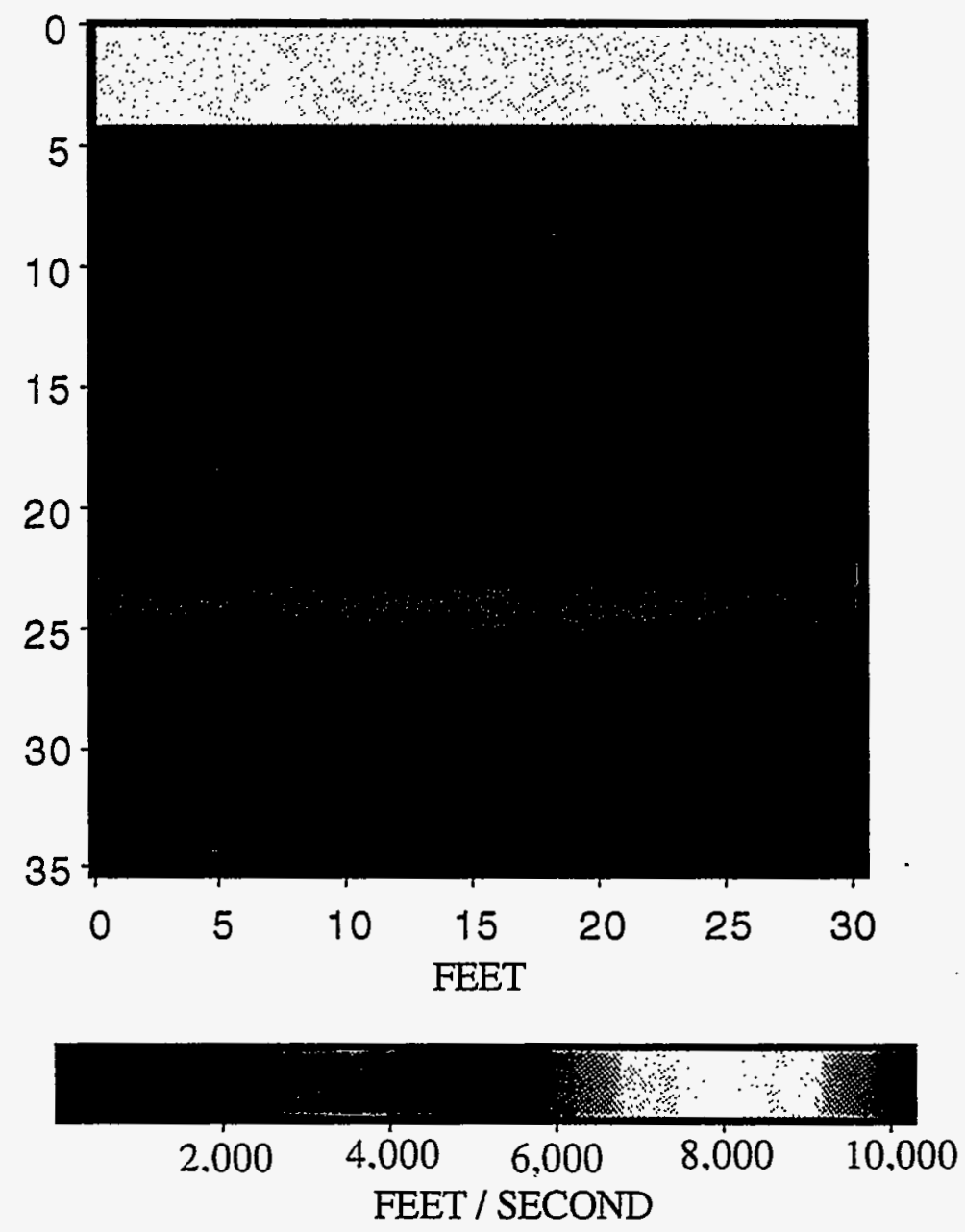

Figure 11. A Hanford tank 1-D velocity model. The top layer is a salt cake $(8,000 \mathrm{ft} / \mathrm{sec})$ over a fluid layer $(5,000 \mathrm{ft} / \mathrm{sec})$. Below that is a gradient layer $(5,000$ to $1,200 \mathrm{ft} / \mathrm{sec})$ connecting the fluid to the low velocity sludge layer $(1,200 \mathrm{ft} / \mathrm{sec})$. Beneath the sludge layer is the bottom of the tank with the fast velocity of cement $(11,000 \mathrm{ft} / \mathrm{sec})$. 


\title{
HANFORD WASTE MODEL \#1
}

\author{
TRAVEL TIME
}

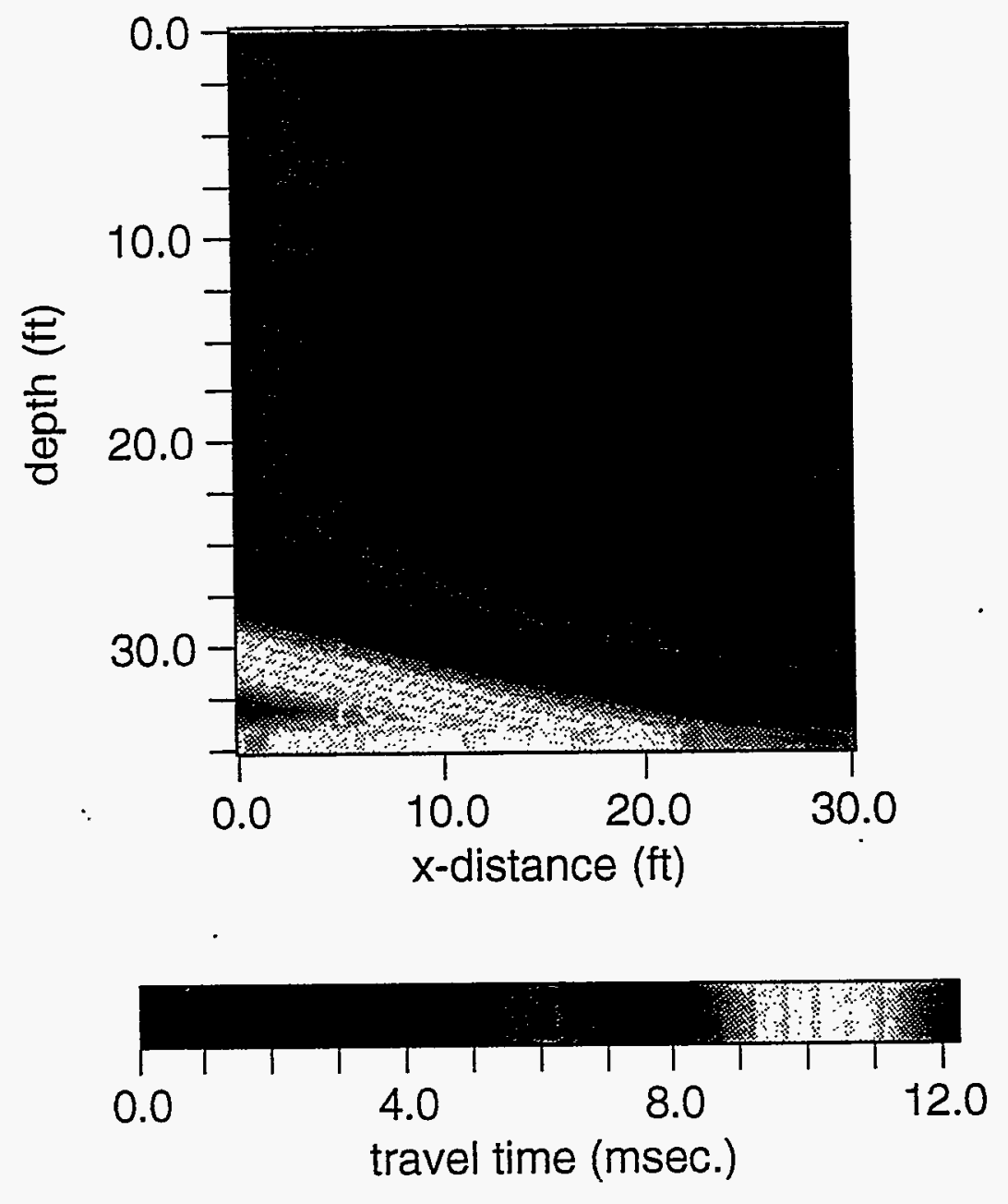

Figure 12. A "map" of first-arrival traveltime from a source at a depth of 17 feet in the right-hand well. The bands in this image show contours corresponding to the position of the first-arrival "wavefront" at various times. Contours are most closely spaced in low-velocity regions. A head wave can be clearly seen propagating from the salt cake in the upper left-hand corner. 


\section{HANFORD WASTE MODEL \#1 TOMOGRAPHIC IMAGE}
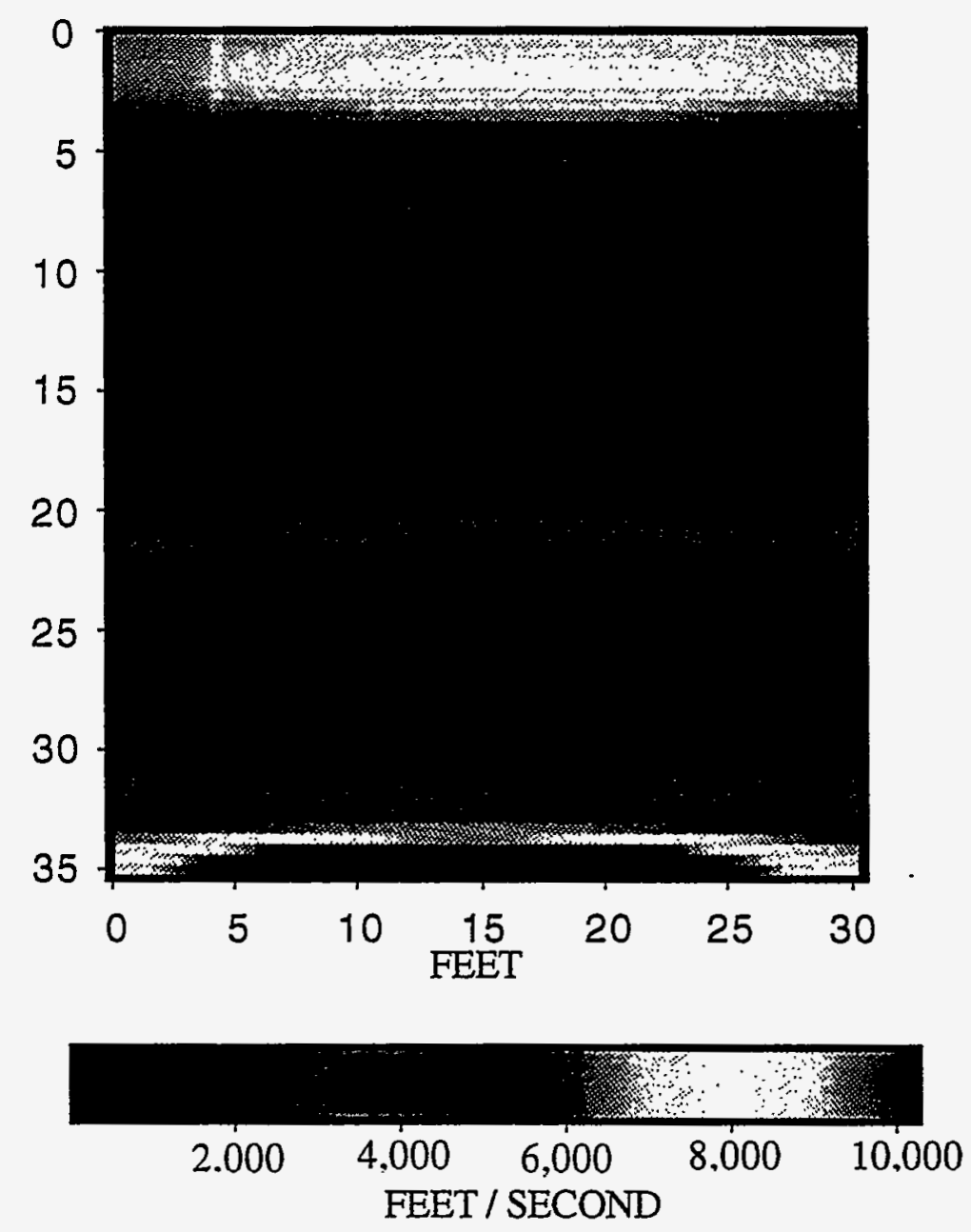

Figure 13. The tomographic image computed from synthetic ray trace data using the model shown in Figure 10. The forward model had 68 receivers placed at half foot intervals along the left vertical edge of the model; and 68 sources at half foot intervals along the right side of the model. The inversion process was a non-linear, ray trace based, travel time inversion. Comparing this tomographic image with the model (Figure 11), it can be seen that the center region between the sources and receivers gives the best results. Artifacts can be seen near the edges close to the sources and receivers. 
WHC-EP-0870, Rev 0

Appendix B

Velocities of Sound in Tank Wastes and Simulants.

A collection of 1 ab measurments 


\section{WHC-EP-0870, Rev 0}

This appendix summarizes the acoustic velocities of Hanfords Underground Storage Tank solids and sludges. These data, collected from four documents, represents actual materials from tank 101-SY and chemically simulated materials from LLNL, Ames Tab, and Texas Tech University.

\section{Sludge}

101-SY Sample

(Ref. 1)

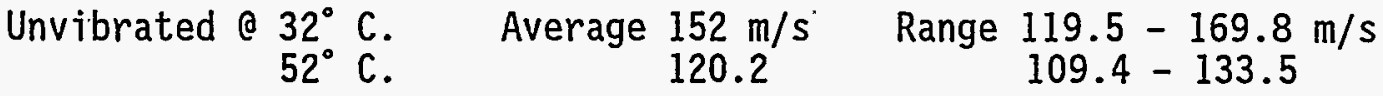

Vibrated $34^{\circ} \mathrm{C}$.

$110.4 \quad 107.9-112.8$

$52^{\circ} \mathrm{C}$.

87.4

$76.2-93.0$

LANL SimuTant:

(Ref. 1)

Unvibrated e $22.2^{\circ} \mathrm{C}$. Average 187.3

$36.7^{\circ} \mathrm{C}$. $\quad 173.3$

$52.8^{\circ} \mathrm{C} . \quad 163.7$

Range $179.7-190.4 \mathrm{~m} / \mathrm{s}$

$170.9-173.2$

$161.9-166$

Vibrated

$52.8^{\circ} \mathrm{C}$.

1338

$38.3^{\circ} \mathrm{C} . \quad 826.3$

$1303-1364$

816.1 - 846.7

STudge Reconstituted from Ames Lab Salt cake: (Ref. 4)

$\begin{array}{lll}\# 3 & \frac{30 \% \text { water }}{2060 \mathrm{~m} / \mathrm{s}} & \frac{50 \% \text { water }}{1710 \mathrm{~m} / \mathrm{s}} \\ \# 4 A & 2140 & 1890 \\ \# 5 & 2180 & 1890 \\ \# 6 & 1970 & 1750\end{array}$

Texas Tech Sludge:

(Ref. 4)

$$
1740 \mathrm{~m} / \mathrm{s}
$$

LANL Measurements: (Reported by $\mathrm{Ha} 11$ '93)

(Ref. 2 \& 3)

$$
\begin{array}{ll}
\text { (no entrained gas) } & 2200 \mathrm{~m} / \mathrm{s} \\
\text { (entrained gas) } & 237 \mathrm{~m} / \mathrm{s}
\end{array}
$$

Page 1 of 2 